\title{
Tested versus code capacity of existing bridges - Three examples
}

\author{
Gabriel Sas
}

Northern Research Institute, Narvik, Norway

Niklas Bagge, Jens Häggström, Jonny Nilimaa, Arto Puurula, Thomas Blanksvärd, Björn Täljsten and Lennart Elfgren

Luleå University of Technology, Luleå, Sweden

Anders Carolin, Björn Paulsson

Trafikverket, Luleå and Borlänge, Sweden

Contact: gabriel.sas@norut.no

\begin{abstract}
This paper presents the results from three tests to failure of different types of bridges: a two span reinforced concrete railway trough bridge; a five-span prestessed concrete beam bridge; and a one span metal railway truss bridge. The results show that the capacity of the structures are underestimated by current standards, while numerical analysis combined with material testing can provide more accurate results. Some examples are also presented on how deficiencies in capacity can be mitigated using fiber reinforced polymer strengthening systems.
\end{abstract}

Keywords: Assessment methods, Strengthening, Bridges, Prestressing, Guidelines, Modelling, Repair, Structural Design, Testing, Life Cycle Assessment

\section{Introduction}

A global engineering challenge is to use our existing structures in an optimal way and not to take them out of service and tear them down before their true real functionality has come to an end. Codes and standards are - and should be conservative but it is one thing to design a new structure - with all unknowns regarding material properties and workmanship - and another thing to assess an existing structure, where properties and performance can be checked and ascertained. So there is a need for codes and standards for existing structures such as the new Swiss codes, [1].
Unfortunately it is much easier for an infrastructure manager to have a new bridge to oversee than to have to take care of an old bridge, where much knowledge and concern is needed to make the right decisions regarding maintenance and upgrading. For that reason bridges are sometimes taken out of service before there really is a need to do so, it is just less trouble for the manager to have it replaced than to have to struggle with it. However, with increased use of Life Cycle Cost Analysis (LCCA) also for maintenance and upgrading work, this practice will hopefully be abandoned and more optimal procedures will be introduced. Examples on how 
this can be done are given in the recent European FP7 Project MAINLINE, 2011-20014 [2].

Tests to failure of existing bridge structures are rare, mainly due to high costs and lack of test objectives. When such an opportunity arises, much more understanding of these structures can be gathered, and a proof of existing design and assessment methods can be obtained.

This paper compiles the experience and results from tests to failure of three different types of bridges. The results are presented with focus on a comparison between the tested capacity and existing methods for assessment based on analytical models from standards and codes.

The results show that code models often underestimate the true capacity while non-linear numerical tools might provide more accurate results when combined with results from material testing.

\section{The Örnsköldsvik Bridge}

\subsection{Background}

This test was scheduled as part of a demonstration of newly developed or upgraded tools for monitoring, assessment and upgrading of structures within the EU financed project Sustainable Bridges 2003-2007 [3].

The studied bridge was a 50 year old RC railway trough bridge located in Örnsköldsvik, Sweden, see Figure 1.
The bridge consisted of two outer beams supporting a slab in two spans $(12+12 \mathrm{~m})$, with a slight longitudinal curvature $(R=300 \mathrm{~m})$ and supports skewed with an angle of 17 degrees. It was taken out of service in 2005 when a new highspeed railway line, the Bothnia Line, was built [4][6]. The bridge was designed for a $40 \mathrm{MPa}$ concrete and steel reinforcement with yield strength of $400 \mathrm{MPa}$. Tested concrete had a mean strength $68,5 \mathrm{MPa}$ (8 $\mathrm{MPa}$ standard deviation) corresponding to a characteristic compressive strength of $57 \mathrm{MPa}$. The reason for the growth is a coarse grinding of the cement which prolonged the hydration process after the 28 days, when the original concrete was tested. The steel reinforcement tests showed yield strengths slightly above $400 \mathrm{MPa}$ and ultimate strengths up to $700 \mathrm{MPa}$.

\subsection{Test-setup and capacity assessment}

The bridge was tested with two hydraulic jacks, placed on top of a loading beam. They exerted a downward force on the loading beam by pulling on steel tendons anchored in the bedrock to a depth of $9 \mathrm{~m}$. The loading beam was placed over the middle of the second span and positioned so that its longitudinal axis was oriented transverse to the longitudinal direction of the bridge, see Figure 1. The test setup was designed so that a shear failure would be obtained at the mid longitudinal section of the loaded span.

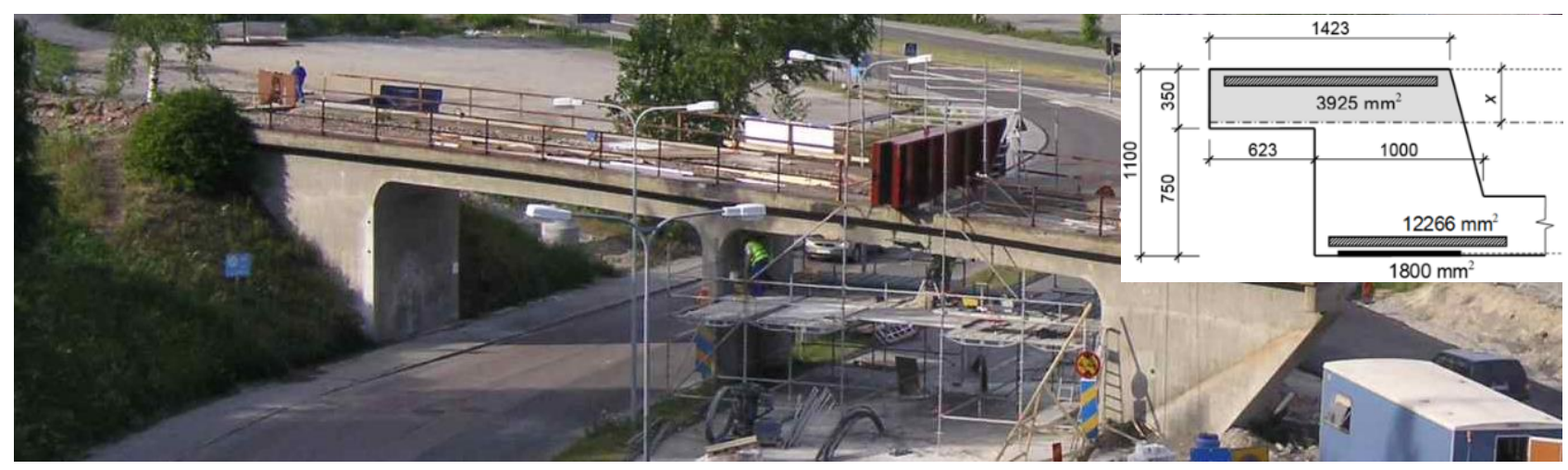

Figure 1. The tested railway bridge in Örnsköldsvik, Sweden. A view from the West side showing the test setup and, as insert, a typical cross-section [4]-[6]. 
At the time of the test four standards were used to assess the capacity of the bridge: the Swedish standard BBK 04 [7], the US standard $\mathrm{ACl} 318$ [8] the European standard EC2 [9] and the Canadian standard CSA [10].

To obtain a shear failure, the bridge was strengthened before the final failure test with 18 (nine per beam) $10 \mathrm{~m}$ long near surface mounted (NSM) carbon fiber reinforced polymers (CFRP) bars, each with a $10 \times 10 \mathrm{~mm}$ cross section. The modulus of elasticity and the tensile strain at failure were $250 \mathrm{GPa}$ and $0,8 \%$, respectively [4], [5].

\subsection{Test results and comparison with codes}

The failure was relatively ductile, Figure 2 , and the bridge was intact after the test finished. The recorded failure load $P$ was $11,7 \mathrm{MN}$. The mechanism of failure was a simultaneous bondbending-shear failure, resulting in the formation of flexural-shear cracks in both beams at an angle of about $\theta \approx 32^{\circ}$. The NSM reinforcement played a major role in the failure process. The video recorded during the test shows that intermediate crack debonding of the NSM initiated the shearbending failure.

The shear force capacity obtained using the three earlier mentioned major standards, i.e. US, European and Canadian [8]-[10], is compared with the test result. The codes were selected because they are based on the three major theories currently used in the design and assessment process of the shear force capacity of structural elements: the fixed angle truss model $\left(45^{\circ} \mathrm{TM}\right)$, the variable angle truss model (VAT), and the modified compression field theory (MCFT), respectively. Values for the flexural capacity of the bridge before and after strengthening are used here for calculating the shear force bending moment interaction for one beam, and the shear capacity is considered to be similar for the other beam.

The code capacities were determined using linear finite element analysis calculations considering the interaction between the shear force and the bending moment, as a function of the unit load $P$. Details of the procedures are shown elsewhere [11], here are presented only the results, see
Table 1. $V_{R d}[\mathrm{MN}]$ is the shear capacity of one beam, $P_{V}[\mathrm{MN}]$ is the total applied load causing shear failure and $P_{M}[\mathrm{MN}]$ is the total applied load causing bending failure.

The three codes predict the shear force capacity in a conservative manner. One advantage of using Eurocode is that the VAT model predicts the crack inclination angle quite accurately, but it gives the most conservative estimates of the shear capacity because it does not consider the concrete contribution to the total shear capacity. The ACl model does not consider the flexural shear interaction. The advantage of using this model for such an assessment is that it is simple and provides similar results with less computation time. The CSA model captures the flexural shear interaction in a conservative manner compared to the Eurocode. The shear crack angle predicted by this standard and used in the estimation of the shear force capacity leads to more conservative results for the stirrups' contribution than Eurocode, but higher estimates than the $\mathrm{ACl}$ model.

The authors believe that this is connected to the fact that the longitudinal strain at the middle of the cross-section has been calibrated with test results obtained from steel reinforced concrete beams rather than FRP strengthened beams.

In general, when utilizing FRP to increase flexural capacity, the longitudinal strains increase at the ultimate limit state because the capacity increases.

The Eurocode estimates that this will have a positive effect on the shear capacity, lowering the crack angle and thus activating more shear reinforcement due to cross-sectional equilibrium. This effect is not evident when using the CSA and $\mathrm{ACl}$ approaches, because the influencing factors have been calibrated using data obtained from tests on elements with steel reinforcement, not FRP. Therefore, the CSA will give marginally higher estimates of shear capacity for flexural strengthened specimens, and since the $\mathrm{ACl}$ code does not consider any bending moment shear force interaction, its estimates of the shear capacity will not be affected by including such strengthening. 


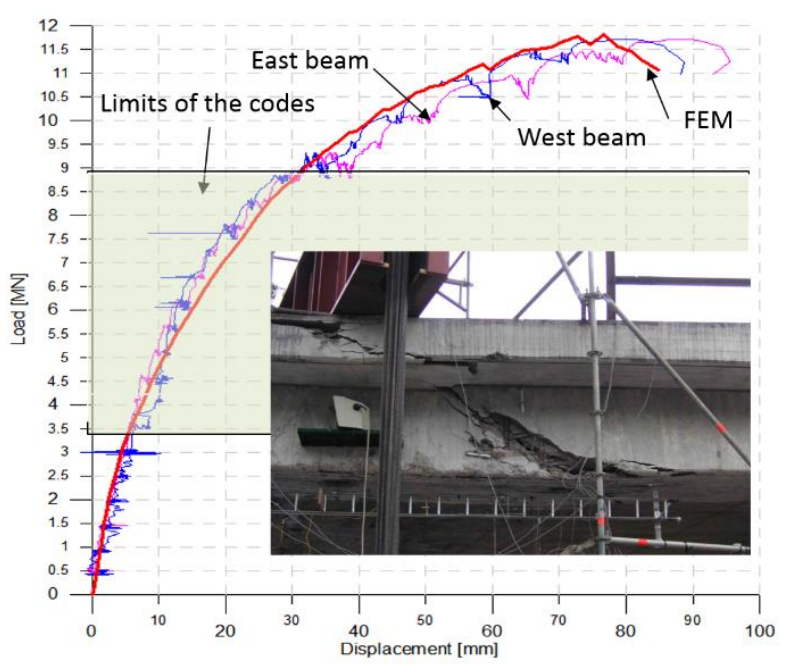

Figure 2. Load-displacement curves as recorded and as calculated with nonlinear FEM and crack pattern in the SE beam after failure.

Table 1. The capacities and the failure loads predicted by the compared standards for the strengthened bridge.

\begin{tabular}{lcccccc}
\hline & & $\mathrm{EC2}$ & & $\mathrm{CSA}$ & $\mathrm{ACl}$ & Test \\
\hline$\theta$ & $21^{\circ} 8^{\prime}$ & $45^{\circ}$ & $33^{\circ} 8^{\prime}$ & $37^{\circ} 9^{\prime}$ & $45^{\circ}$ & $\approx 32^{\circ}$ \\
\hline$V_{R d}[\mathrm{MN}]$ & 2,54 & 1,02 & 1,52 & 2,28 & 2,29 & - \\
\hline$P_{V}[\mathrm{MN}]$ & 9,12 & 3,64 & 5,44 & 7,67 & 7,74 & 11,7 \\
\hline$P_{M}[\mathrm{MN}]$ & 6,64 & 6,64 & 6,64 & 6,64 & 6,64 & 11,7 \\
\hline
\end{tabular}

\section{The Kiruna Bridge}

\subsection{Background}

A 55 year-old five-span prestressed concrete girder bridge, located in Kiruna, Sweden, had been monitored from 2006 due to large ground deformations, which were caused by mining activities. In 2014 the bridge, see Figure 3, was the object of an extensive experimental programme, including the performance of two types of strengthening systems using carbon CFRP materials. The complete experimental programme is reported in Bagge et al [12], [13], [17].

The bridge was a $121,5 \mathrm{~m}$ long and 15,6 $\mathrm{m}$ wide viaduct with five spans. The superstructure consisted of three parallel girders (height: 1923 $\mathrm{mm}$, width: $410 \mathrm{~mm}$ ), connected with a deck slab

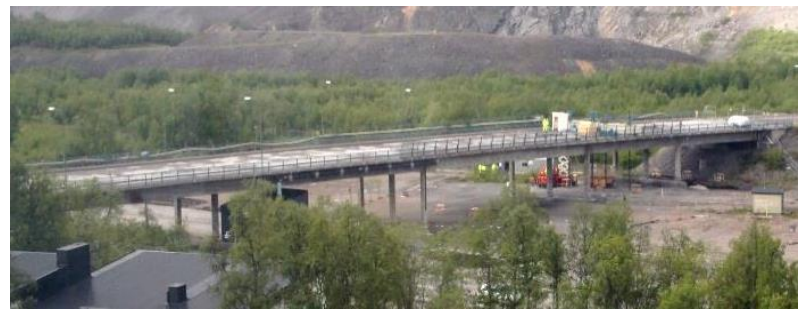

Figure 3. Photograph of the Kiruna Bridge tested to failure [12], [13].

(thickness at girder: $300 \mathrm{~mm}$; thickness $1 \mathrm{~m}$ from the girder: $220 \mathrm{~mm}$ ). Six BBRV tendons per girder were post-tensioned. Each tendon was composed by 32 strands with a diameter of $6 \mathrm{~mm}$. The bridge was designed for a $28,5 \mathrm{MPa}$ concrete and steel reinforcement with yield strength of 400 or 600 $\mathrm{MPa}$. The tendons had a nominal yield stress of $1450 \mathrm{MPa}$ and a failure stress of $1700 \mathrm{MPa}$ [13].

\subsection{Test of main girders and capacity assessment}

In the second span from West two of the girders were loaded to failure for investigation of the structural behaviour and load-carrying capacity. Additionally, the behaviour of the superstructure was studied in several preloading stages, both strengthened and unstrengthened.

Finite element (FE) analyses were performed in order to predict the structural behaviour and the load-carrying capacity. The softwares Atena and Abaqus with $a$ 2D and 3D idealization, respectively, were used. Figure 4 shows the loaddisplacement curve for the failure test and the two FE analyses, total load versus midspan deflection of the central girder.

The first step in the test was equal loading of all three girders up to a total load of $12 \mathrm{MN}$, followed by loading the southern and the central girder to failure. At failure of the southern and central girder the total load was $13,5 \mathrm{MN}$ and $12,8 \mathrm{MN}$, respectively. Predictions with linear elastic analysis in combination with an explicit check according to Eurocode [9], models for the flexural moment and shear force resistance resulted in a load-carrying capacity about half of the load given by the test.

The longitudinal reinforcing steel yielded already in the preloading of the bridge (up to $6 \mathrm{MN}$ ), 
followed by yielding of several stirrups. In both girders a combined shear and flexural failure occurred including yielding of longitudinal reinforcement, concrete crushing and ultimately stirrup rupture. The girders behaved in a ductile manner and after the test they still had an appreciable residual load-carrying capacity, see Figures 4 and 5 .

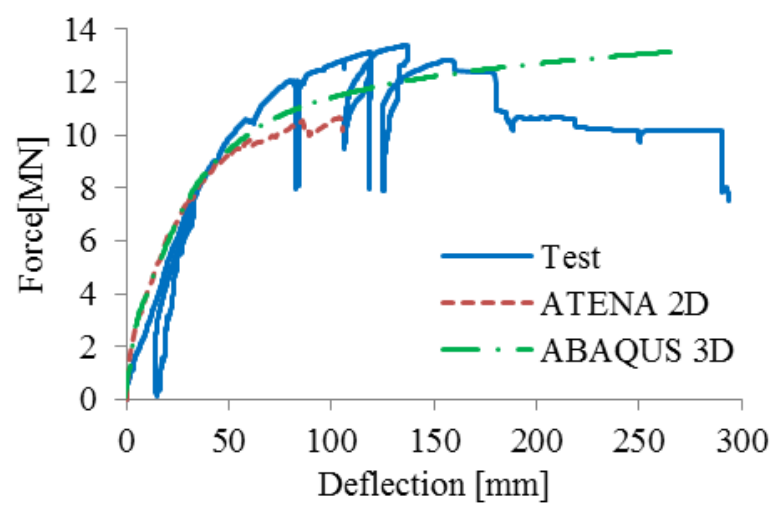

Figure 4. Load-deflection curve for the failure test of the bridge girders [13], [14].

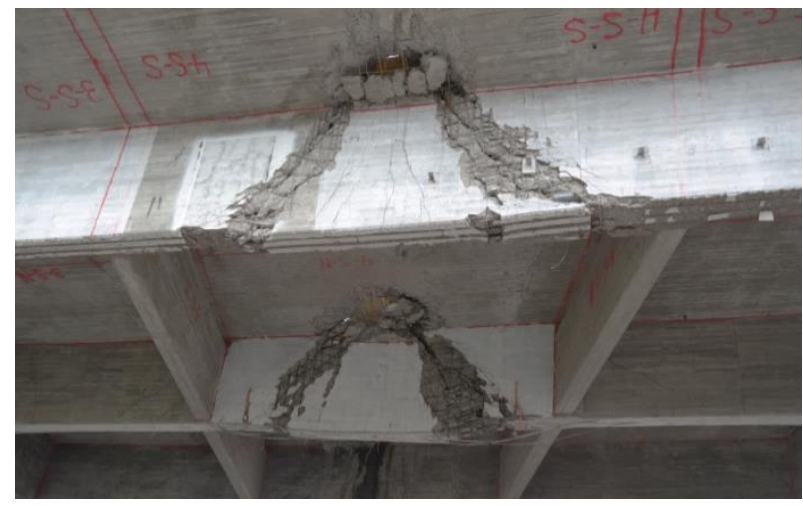

Figure 5. Photograph of the girders after test [13], [14].

\subsection{Test of deck slab test capacity assessment}

Adjacent to the northern girder, not loaded to failure in previous girder tests, the behaviour and load-carrying capacity of the deck slab was investigated by loading it to failure.

Figure 6 shows the deck slab after the test, illustrating the failure under the western loading plate. The total load was 3,32 MN (1,66 MN per loading plate) and it suddenly failed in shear and punching, without any forewarning.



Figure 6. Photograph of the deck slab after test.

The test demonstrated a load-carrying capacity two times larger than the outcome from the analytical analysis given by the punching model in the Eurocode [9]. This indicates that the analytical model did not fully predict the behaviour of the tested bridge slab. For instance, the influence of important conditions such as flexible supports, i.e. the girders, and membrane action is disregarded in the analytical model.

\section{The Åby Bridge}

\subsection{Background}

The Åby Bridge was a 33 meter long steel truss railway bridge located in a rural area in the northern parts of Sweden. It was built in 1957, in the transition period from riveted to welded bridges. The bridge was therefore partially riveted and partially welded. The bridge was designed for a single track with a load of type F46 (12 axles of 25 tons for the locomotive and a distributed load of $85 \mathrm{kN} / \mathrm{m})$, Häggström and Blanksvärd [15].

The capacity of the Åby Bridge was assessed in 1994. The procedure showed that the fatigue capacity in the joints between the wind truss and the main truss was exceeded. However field investigations did not reveal any cracks and therefore no structural rehabilitation took place. When the Swedish Traffic Administration decided to replace the track and superstructure of the Åby Bridge, measurements were performed during the autumn of 2012 just before the bridge was taken out of service. Then the bridge was placed beside the track on temporary supports and tested to failure during the autumn of 2013 [15]. 


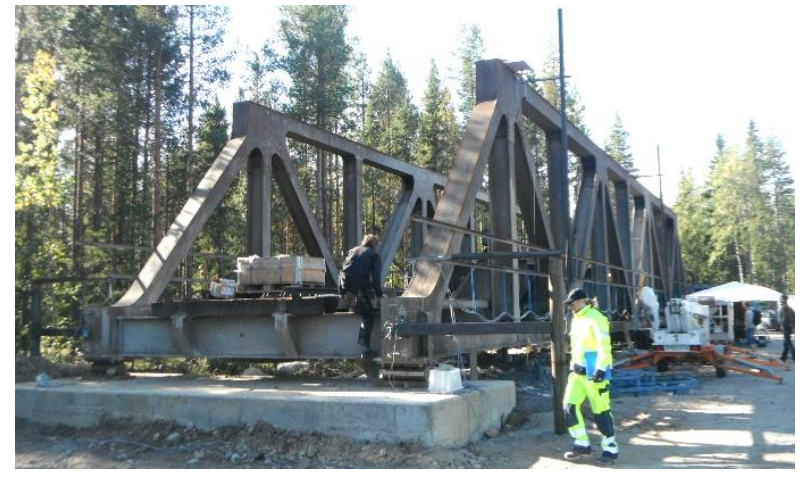

Figure 7. Test of a 55 year old $33 \mathrm{~m}$ long metallic bridge at Åby River in 2013. Overview of test site.

\subsection{Test-setup and capacity assessment}

The loading on the bridge was induced by two hydraulic jacks with cables anchored in bed rock similar to the Örnsköldsvik Bridge presented above. In order to simulate the loading of a wagon, two girders were used to distribute the load into four equal loads each.

The static testing consisted of 18 load series where the last load scenario was loading until failure of the bridge. The steel had a nominal yield stress of $270 \mathrm{MPa}$ in the main truss and cross girders and $240 \mathrm{MPa}$ elsewhere. Tested mean values were some $20 \%$ higher, 323 and $304 \mathrm{MPa}$ respectively.

Some 140 sensors (strain gauges, LVDT's and temperature gauges) were mounted in order to monitor the structural behavior of the bridge.

The results from a new assessment performed in accordance with the Swedish standards [16] have indicated that the bridge had sufficient capacity at ultimate limit state but not at fatigue, most likely due to inexperience with fatigue in welded details at the time when the bride was designed. A refined fatigue assessment showed that the fatigue capacity was exceeded in the connection between the longitudinal stringers and the stabilizing horizontal truss, where the connection plate is welded to the flange of the longitudinal stringer, see Figure 8 . There were however no visible cracks at these details, although the Palmgren-Miner damage hypothesis shows an accumulated damage exceeding 5 , which means that the designed lifespan is exceeded 4 times. This deficiency had potentially severe consequence on all other bridges built at similar times.

In order to estimate the ultimate capacity a detailed FEM model was developed with the Abaqus software. The model consists of shell elements considering all connections as rigid [15].

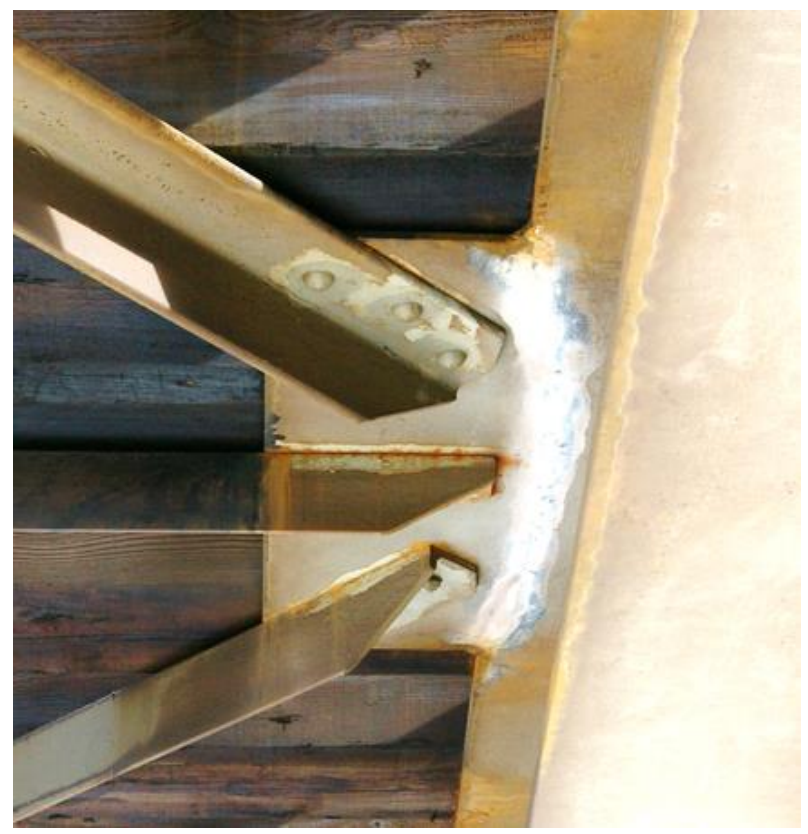

Figure 8. Connection for the horizontal bracing which makes the longitudinal stringers sensitive for fatigue [15].

\subsection{Test results and comparison with codes}

Non-linear deformations started at about $8 \mathrm{MN}$ and continued up to $11 \mathrm{MN}$ when the top cord buckled, see Figure 9 .

The capacities were studied as obtained from the failure test and from the numerical analysis. Initially the FEM was carried out using design values as input for the material properties. Later on, when material tests were available, the input was updated and a new analysis was performed. It can be observed that the real behavior of the structure fits somewhere in between the two FEM results at the point of yielding. The FEM-results with updated material parameters have approximately the same peak load as the one from the tests. Nevertheless the non-linear behavior recorded during the tests was not accurately described by FEM. 
Since the load added to the bridge only corresponded to one wagon, the load level for a whole train set is compared for a certain number of points. The loading is compared for the normal force in the top cord. Here the loading can be observed from a train set F46 (which is the train set it was designed for) and the loading according to current standards (Eurocode) for new bridges along the line subjected to the heaviest axle loads in Sweden (Load model 71 with $\alpha=1,6$ ). Safety or dynamic amplification factors are disregarded. The comparison shows that the bridge could withstand loading that substantially exceeds both the load it was designed for as well as the load the model in use today before failing. See Figure 9 .



Figure 9. Deflection at mid span. The figure also shows the expected outcome based of the simulation

Even though the regulated axle load on the route (25 tons) was exceeded approximately 4 times before having a non-linear behavior for the deflection in mid span and almost 6 times for the ultimate load, the structural behavior of the Åby Bridge remained ductile with a non-dramatic failure without fatigue induced failures in any joints.

\section{Conclusions}

The results of three tests to failure of three different bridges were presented. The tests were carried out on decommissioned structures deemed for demolition. Numerical tools are proven to be reliable instruments for assessment especially when combined with material testing. All the tested structures had a considerable "hidden" capacity which is little reflected during ordinary assessment processes and which is accounted for neither in standards nor in design guidelines. Perhaps some of these differences arise from redistribution of loads during the testing in the statically indeterminate structures. Another reason is the high safety factors that are used both for loads and materials.

\section{Acknowledgement}

The authors gratefully acknowledge financial support from the European Union, Trafikverket, LKAB/HLRC, SBUF and Luleå University of Technology (LTU). They also thank their colleagues and collaborators who have worked in these projects and especially Joan $\mathrm{R}$ Casas at the Universitat Politècnica de Catalunya, Barcelona, Spain, and the Swedish Universities of the Built Environment (Oskar Larsson and Sven Thelandersson, LTH; Kent Gylltoft, Karin Lundgren and Mario Plos, Chalmers; and Raid Karoumi, Mikael Hallgren and Håkan Sundquist, KTH) for fruitful cooperation.

\section{References}

[1] SIA 269, Existing structures. A series of Swiss Codes. Zürich: Swiss Society of Engineers and architects, (2011): SIA 269:2011 Grundlagen der Erhaltung von Tragwerken (In German) English version: Existing structures - Basis for examination and interventions, 24 p. SIA 269/1:2011 Erhaltung von Tragverken - Einwerken (Actions. In German), 24 p. SIA 269/2:2011 Betonbau (Concrete. In German), 44 p. SIA 269/3 Stahlbau (Steel. In German). SIA 269/4 Stahl-Beton-Verbundbau (Composite structures. In German). SIA 269/5 Holzbau (Timber/Wood. In German). SIA 269/6 Mauerwerksbau (Masonry. In German). SIA 269/7 Geotechnik (Foundation Engineeering. In German).

[2] MAINLINE, MAINtenance, renewal and Improvement of rail transport INfrastructure 
to reduce Economic and environmental impacts. A European FP7 Research Project during 2011-2014. Some 20 reports are available at http://www.mainlineproject.eu/

[3] Sustainable Bridges, Assessment for Future Traffic Demands and Longer Lives. A European FP 6 Integrated Research Project during 2003-2007. Four guidelines and 35 background documents are available at www.sustainablebridges.net: Inspection and Condition Assessment, ICA, 259 p.; Load and Resistance Assessment of Railway Bridges, LRA, 428 p.; Guideline for Monitoring of Railway Bridges, MON, 83 p.; Guide for use of Repair and Strengthening Methods for Railway Bridges, STR, $139 \mathrm{p}$.

[4] Elfgren L, Enochsson O, Puurula A, Thun H. Field Test of a Concrete Bridge in Örnsköldsvik. SB-7.3 Sustainable Bridges. Luleå: Sustainable Bridges; 2008, 406 p. www.sustainablebridges.net

[5] Puurula, A, Load-carrying Capacity of a Strengthened Reinforced Concrete Bridge: Non-linear Finite Element Modeling of a Test to Failure. Assessment of Train Load Capacity of a Two Span Railway Trough Bridge in Örnsköldsvik Strengthened with Bars of Carbon Fibre Reinforced Polymers (CFRP). Doctoral Thesis, Luleå: Luleå University of Technology, 2015, 332 p http://pure.Itu.se/portal/en/

[6] Puurula, A, Enochsson, O, Sas, G, Blanksvärd, $T$, Ohlsson, $U$, Bernspång, $L$, Täljsten, B, Carolin, A, Paulsson, B, Elfgren, $L$, Assessment of the Strengthening of an RC Railway Bridge with CFRP Utilizing a FullScale Failure Test and Finite-Element Analysis, J. Struct. Engineering, ASCE, 2015, 141, D4014008, $11 \mathrm{p}$.

[7] Boverket. Handbok om betongkonstruktioner BBK 04 (Guidelines for concrete structures. In Swedish) Karlskrona, Sweden: Boverket 2004. p. 271.

[8] $\mathrm{ACl}$ Committee 318. Building Code Requirements for Structural Concrete (ACl
318-05) and Commentary (ACl 318R-05): American Concrete Institute; 2005.

[9] CEN. Eurocode 2: Design of concrete structures Part 1-1: General rules and rules for buildings. Brussels, Belgium: European Committee for Standardization; 2005. p. 225.

[10] CSA. CSA-A23.3 Design of concrete structures. Mississauga, Ontario, Canada: Canadian Standards Association; 2009. p. 352.

[11] Sas, G, FRP Strengthening of reinforced concrete beams. Doctoral Thesis, Luleå: Luleå University of Technology, 2011, 248 p. http://pure.Itu.se/portal/en/

[12] Bagge N, Nilimaa J, Blanksvärd T, Elfgren L. Instrumentation and Full-Scale Test of a Post-Tensioned Concrete Bridge. Nordic Concrete Research. 2014;51:68-83.

[13] Bagge, N, Assessment of concrete bridges. Models and tests for refined assessment. Licentiate thesis, Luleå University of Technology, 2014, 132 p. http://pure.Itu.se/portal/en/

[14] Nilimaa, J, Concrete Bridges: Improved Load Capacity. Doctoral Thesis, Luleå: Luleå University of Technology, 2015, 176 p http://pure.ltu.se/portal/en/

[15] Häggström, J and Blanksvärd, Th, Assessment and full scale failure test of a steel truss bridge. IABSE Workshop Helsinki 2015: Safety, Robustness and Condition Assessment of Structures, Zûrich: IABSE, 288-295.

[16] BVS 583.31. Bärighetsberäkningar av järnvägsbroar (Assessment of railway bridges, in Swedish). Sweden: Swedish Rail Administration; 2005.

[17] Bagge, N, Nilimaa, J, Blanksvärd Th, Bernspång L, Täljsten B, Sas G, Tu, Y, Carolin $C$, Elfgren L, Performance of a prestressed concrete bridge loaded to failure. IABSE Conference Geneva 2015: Structural Engineering - Providing Solutions to Global Challenges, 8 pp. 